\title{
Pathline density distributions in a Null-Space Monte Carlo approach to assess groundwater pathways
}

Christian Moeck*1, John Molson², Mario Schirmer ${ }^{1,3}$

Contact: Christian.moeck@eawag.ch

*Corresponding author

${ }^{1}$ Eawag, Swiss Federal Institute of Aquatic Science and Technology, Dübendorf, Switzerland

${ }^{2}$ Département de géologie et de génie géologique, Université Laval, Québec City, Canada

${ }^{3}$ Centre of Hydrogeology and Geothermics (CHYN), University of Neuchâtel, Neuchâtel, Switzerland

Conflict of interest: None

Keywords: Groundwater flow, Groundwater modeling, Particle tracking, Inverse stochastic modeling, Uncertainty analysis, Water supply protection

Article Impact Statement: An inverse stochastic modeling approach with particle tracking provides probability information beyond classical deterministic approaches

This document is the accepted manuscript version of the following article: Moeck, C., Molson, J., \& Schirmer, M. (2020). Pathline density distributions in a null-space Monte Carlo approach to assess groundwater pathways. Groundwater, 58(2), 189-207. https://

doi.org/10.1111/gwat.12900 


\begin{abstract}
A Null-Space Monte-Carlo (NSMC) approach was applied to account for uncertainty in the calibration of the hydraulic conductivity $(K)$ field for a three-dimensional groundwater flow model of a major water supply system in Switzerland. The approach generates different parameter realizations of the $K$ field using the pilot point methodology. Subsequently, particle tracking (PT) was applied to each calibrated model, and the resulting particles are interpreted as the spatial pathline density distribution of multiple sources. The adopted approach offers advantages over classical PT which does not provide a means for treating uncertainty originating from the incomplete description of subsurface heterogeneity. Uncertainty in the $K$ field is shown to strongly influence the spatial pathline distribution. Pathline spreading is particularly evident in locations where the information content of the head observations does not sufficiently constrain the estimated parameters. Despite the predictive uncertainty, the pumped drinking water at the study site is most likely dominated by artificially-infiltrated groundwater originating from the local infiltration canals. The model suggests that within the well field, the central pumping wells could be extracting regional groundwater, although the probability is relatively low. Nevertheless, a rigorous uncertainty assessment is still required since only a few realizations resulted in flow paths that support the field observations. Model results should therefore not be based on only one model realization; rather, an uncertainty analysis should be carried out to provide a sufficiently large suite of equally probable simulations that include all potential sources and pathways.
\end{abstract}

\title{
Introduction
}

The protection of groundwater resources remains an issue of high local and global importance (Frind and Molson 2018). Drinking-water production wells near contaminant sources, or which might intersect contaminant pathways, for example, is a common concern for water 
resource managers (Baillieux et al. 2015). Improved knowledge regarding flow and transport processes in the subsurface is therefore critical for developing science-based sustainable water management strategies (Izady et al. 2017; Llopis-Albert et al. 2016).

In this context, groundwater modeling is routinely used for environmental management and investigations (James et al. 2009), and can increase the understanding of environmental processes. Given the predictive capability of groundwater models, they are often the only viable means of providing input to water management decisions, as they can predict the impacts of a specific water management strategy (Gorelick and Zheng 2015) and provide a tool to understand mechanisms of groundwater circulation such as mixing between different aquifer systems (Demlie et al. 2007). To obtain reliable predictions, representative physical parameters, including their spatial distribution or heterogeneity, are required for describing the subsurface. Subsurface heterogeneity indeed plays a critical role in controlling groundwater flow and transport processes (Dogan et al. 2014; Doherty 2003; Sudicky and Huyakorn 1991). Variations in hydraulic conductivity $(K)$, for example, can lead to changes in groundwater flow directions and velocity which in turn can affect transport migration behavior (Zheng and Gorelick 2003). Thus, $K$ is typically the most investigated parameter in every site characterization plan (Butler et al. 1999; Butler et al. 2003).

Various field methods of studying the spatial distribution of $K$ in the subsurface can be applied, such as analysis of the grain size distribution of the aquifer material (Devlin 2015; Strasser et al. 2015), use of flow meters (Busse et al. 2016), slug tests (Butler et al. 2007; Butler and Zhan 2004), hydraulic tomography (Brauchler et al. 2012; Illman 2014; Illman et al. 2008; Schwede et al. 2014) and direct push techniques (Liu et al. 2012; Zschornack et al. 2013). Moreover, pumping tests (Butler 2009; DesRoches and Butler 2016) can provide information about $K$ over larger scales. Despite the wide variety of methods for measuring $K$, subsurface heterogeneity can never be investigated in all its detail. Nevertheless, to describe 
and predict subsurface processes, applied models typically force us to create a continuous 3D conceptualization and corresponding parameter distributions, while field data are generally discrete. The shape of these parameter distributions and their values are also typically nonunique and subject to uncertainty. Commonly-required groundwater model calibrations can, therefore, introduce uncertainty in model predictions (Moeck et al. 2015; Sepulveda and Doherty 2015), with the result that in many cases, several different model parameter sets are able to reproduce the observations within given confidence limits linked to data measurement errors. Due to this non-uniqueness, no single (or best) calibrated model can be identified; instead, a suite of different parameter realizations will fit the observations equally well (Dausman et al. 2010). Assessing this uncertainty based on multiple parameter realizations is, however, still rarely carried out, although several computationally efficient methods have been developed in recent years (Asher et al. 2015; Oliver and Chen 2011; Renard 2007; Zhou et al. 2014).

Among the many available numerical methods, particle tracking (PT) is commonly applied to simulate flow and transport migration, to delineate wellhead protection areas, and to identify contaminant source locations and pathways (Riva et al. 2006). With the PT approach, a groundwater model is applied and particles along the flow lines are tracked over time. In contrast to advective-dispersive transport modeling, advection-based PT methods are less computational demanding (Alberti et al. 2018). The basic PT approach, however, has several limitations, the most important being that it does not consider subsurface uncertainty which can lead to misleading results (Frind and Molson 2018; Hunt et al. 2001).

The objective of this study is therefore to evaluate uncertainty, with respect to the groundwater flow direction, originating from the incomplete description of a heterogeneous $K$ field. This uncertainty is here determined through model calibration for a case study in Switzerland, where drinking-water production wells are close to several landfills and 
industrial areas (Moeck et al. 2017b). To protect the pumping wells, an artificial groundwater recharge system is currently being used at this site. Because the artificial recharge rates are twice as high as the pumping rates, an elevated local groundwater mound has developed, serving as a barrier to the natural inflow of potentially contaminated groundwater from adjacent areas (Auckenthaler et al. 2010; Moeck et al. 2016). Nevertheless, a range of chlorinated hydrocarbons have been observed in the pumped groundwater and in nearby monitoring wells (Moeck et al. 2016). These chlorinated hydrocarbons have not been found in the infiltrated surface water, while the highest concentrations of these components have been detected mainly in sampling locations which intersect regional groundwater flow (Moeck et al. 2017c). Therefore, understanding the subsurface heterogeneity and its effect on flow and transport processes is important to ensure a secure production of drinking water. This understanding is critical for effective water management, for which tracking sources and contaminant distribution patterns is a challenging task due to uncertain flow and transport pathways (Hunkeler et al. 2012; Srivastava and Singh 2015). As a result, water resourcemanagement decisions are often based on uncertain assumptions about contaminant distribution patterns which are typically not incorporated into the assessment of risks associated with different proposed management scenarios (Freeze et al. 1990). Here, risk is defined as the probability of unwanted events or system behavior.

For our study area, a three-dimensional (3D) groundwater flow model is first calibrated using the inverse parameter estimation code PEST (Doherty 2011). Subsequently, a Null-Space Monte-Carlo (NSMC) method is used to generate different realizations of the hydraulic conductivity field, each of which leads to a similar model fit between observed and simulated hydraulic heads (Keating et al. 2010; Tonkin and Doherty 2009). Spatial variations in $K$ are obtained by using the pilot point methodology (Dausman et al. 2010; Doherty 2003; Lavenue and de Marsily 2001; Vesselinov et al. 2001). The approach provides great flexibility when 
calibrating heterogeneous systems without neglecting expert knowledge when regularization is used in conjunction with pilot points (Klaas and Imteaz 2017; Moeck et al. 2015). In practice, however, the hydraulic conductivity field is to a large degree unknown and poorly constrained due to limited field data. Different realizations of the generated heterogeneous $K$ field can therefore lead to differences in the flow predictions. Following the proposed workflow of Alberti et al. (2018), this uncertainty is accounted for by applying backward particle tracking to each calibrated model, and the density of the resulting particles are interpreted as the spatial pathline density distribution of multiple sources.

Although uncertainty in the hydraulic conductivity field is expected to play a dominant role in pathline distributions, additional sources of uncertainty beyond the aquifer properties can also be important. The uncertainty of capture zone geometry due solely to the hydraulic conductivity field may be eclipsed, for example, by the uncertainty due to poorly known boundary conditions and future stresses. While explicitly accounting for uncertainty in boundary conditions will increase the complexity and time demand of a model, if boundary condition uncertainty is the main contributor to predictive uncertainty, it is very likely that the hydraulic conductivity field estimates will compensate for incorrect boundary conditions (Doherty and Welter 2010, Peeters and Turnadge 2019).

Thus in this paper, besides evaluating the effect of uncertainty in hydraulic conductivity on pathline distribution, the importance of the chosen boundary conditions for flow predictions is also investigated by applying a linear uncertainty approach (Dausman et al. 2010, James et al. 2009, Moore and Doherty 2005). A linear approach is more computationally efficient than nonlinear approaches (e.g. nonlinear NSMC). Optimal (calibrated) parameter values are not required, the only requirement is the sensitivity of model parameters to model outputs that correspond to observations. As actual data values are not required, the sensitivity of model parameters to the corresponding observations used in the calibration dataset is thereby easily assessed. The drawback, however, is that a linear relationship between model outputs and 
parameters is assumed, which can introduce errors into the analysis of nonlinear models. Nevertheless, some studies show that results from linear and nonlinear uncertainty approaches are comparable and can be used as a supplement for nonlinear methods (e.g. Brunner et al. 2012).

This study provides insights into the reliability of predicting flow and transport directions based on how uncertainty in the subsurface heterogeneity can affect the assessment of risks for an important drinking water supply site in Switzerland. Other uncertainties and factors influencing the results (such as the worth of different observations, and the effect of model simplification, among others) are not considered in this study.

\section{Study area and hydrogeology}

The study site is close to Basel in northern Switzerland (Figure1a), and covers an approximately $10 \mathrm{~km}^{2}$ area of mainly urban and industrial zones (Figure1b). The average annual precipitation is $730 \mathrm{~mm}$, and the mean temperature is $11.5^{\circ} \mathrm{C}$. Surface elevations (from south to north) range from around $290 \mathrm{~m}$ above sea level (masl) to 250 masl near the Rhine River.

The geological units at the study site are (from the bottom to the top) Lower Muschelkalk, Middle Muschelkalk, Upper Muschelkalk, Keuper, Jurassic strata, Tertiary sediments and unconsolidated Quaternary cover (Figure 1). The top of the marly Lower Muschelkalk is used as the lower boundary of the hydrogeological model (Moeck et al. 2017a). The Middle Muschelkalk consists mainly of dolomites, marls, clays, and evaporates (sulphate zone in Figure 1). Subsequently, the Upper Muschelkalk is characterized by a regionally important fractured and karstified limestone aquifer. The mean hydraulic conductivity is $11.23 \mathrm{~m} \mathrm{~d}^{-1}$ (Gürler et al. 1987; Spottke et al. 2005) but can vary between $0.17 \mathrm{~m} \mathrm{~d}^{-1}$ and $86.4 \mathrm{~m} \mathrm{~d}^{-1}$. The Keuper, Jurassic and Tertiary strata represent an aquiclude due to their low hydraulic conductivity. The bedrock units are covered by unconsolidated Quaternary sediments which 
form an unconfined fluvio-glacial sand-gravel aquifer. The average hydraulic conductivity of the sand-gravel aquifer is in the order of $267.8 \mathrm{~m} \mathrm{~d}^{-1}$ (Spottke et al. 2005). The south-eastern shoulder of the Upper Rhine Graben is located in the western part of the study area. This socalled flexure zone is intensely deformed. The $K$ of the fractured flexure zone is unknown and is likely spatially variable. This fracture zone may represent a separate flow path due to its higher permeability or it may be filled with fine sediments forming a hydraulic barrier (Gürler et al. 1987). The two most hydrogeologically relevant units are the aforementioned Quaternary and the Upper Muschelkalk, representing two important aquifers (Moeck et al. 2016). Groundwater flow is from southeast to northwest in the direction of the Rhine River (Figure 1c). Due to the low hydraulic conductivity of the Middle Muschelkalk (sulphate zone) together with a decreasing thickness of the Upper Muschelkalk, upwelling of regional groundwater into the Quaternary aquifer can occur (Figure 1d) (Moeck et al., 2016). For our study area, Spottke et al. (2005) speculated that water extracted by large-scale industrial pumping must contain water fractions from the deeper Muschelkalk aquifer. They noticed that the productivity of industrial pumping wells could only be maintained by groundwater recharge from adjacent horsts, inducing a deeper flow system with local upwelling. Besides being influenced by the geological structure, groundwater flow is also affected by the Rhine and Birs Rivers, groundwater pumping, and artificial recharge (Moeck et al. 2017c) (Figure 1). Increasing water demand of the city of Basel and decreasing groundwater quality led to the installation of an artificial groundwater recharge system with infiltration channels and ponds (Moeck et al. 2017b) (Figure 1). Along the excavated channels, which are approximately $1.5 \mathrm{~m}$ deep, river water is used to recharge the aquifer. Water is injected at the eastern end of the channels and flows along the natural topographical gradient (east to west). All water injected into the channels infiltrates into the aquifer, with no other outflow. To assess the recharge rates, a water mass balance calculation was carried out. Frequent measurements of the water discharge at selected locations in the channels over a span of a few 
months and during different discharge conditions were made with a magnetic induction water flow meter (Moeck et al., 2017b). These data were paired with continuous records of the water levels in the channels at selected locations from which a discharge-stage relationship was established. In addition, a weir system was used to measure continuous discharge at the inlet of the ponds. Subsequently, a water mass balance was carried out for each section between each pair of measurement points, where the inflow rate was subtracted from the outflow rate. Infiltration was assumed nil where the outflow equalled the inflow, whereas infiltration from the channel into the aquifer was implied for negative mass balances (Moeck et al. 2017b). Based on this calculation, it could be concluded that a large proportion of the infiltration occurs close to the eastern injection point, with only about $25 \%$ of the injected water reaching the west end of the channels (Moeck et al. 2017b).

Artificial recharge at the study site is mainly used to minimize the risk of drinking water contamination (due to the proximity of the well field to landfills and industrial sites) and to increase water availability. Overall, recharge rates are twice as high as the pumping rates from the 33 drinking water wells in the sand and gravel aquifer (Figure 1). Due to the high volume of infiltrated water, a local groundwater mound in the sand and gravel aquifer has developed below the channels, serving as a barrier to natural inflow of potentially contaminated water from adjacent areas to the south (Auckenthaler et al. 2010; Moeck et al. 2016). Moreover, large volumes of groundwater are being pumped for industrial purposes, mainly east of the study site. In total, 82 monitoring wells are located in the sand-gravel aquifer, with a minimum depth of $18 \mathrm{~m}$ and maximum of $54 \mathrm{~m}$ (with an average of around $33 \mathrm{~m}$ ). For the bedrock, 34 monitoring wells have been installed at depths between $10 \mathrm{~m}$ and $112 \mathrm{~m}$ (with an average of around $31 \mathrm{~m}$ ). 


\section{Methodology}

\section{Groundwater model}

The model is briefly described in this subsection; a more detailed description is provided by Moeck et al. (2017a). Geological information (Butscher and Huggenberger 2007; Spottke et al. 2005) and data from more than 1,200 drill logs were used to construct a 3D geological model in GOCAD (Geological Objects Computer Aided Design), which provided the framework to build the groundwater flow model. Six model layers with variable thickness

(Figure 2) are used to represent the different geological units in the groundwater model (using the FEFLOW code, DHI-Wasy GmbH). The model is more finely discretized near sources (e.g., infiltration channels, ponds and rivers) and sinks (e.g., pumping wells) as well as at assumed fracture locations. A total of 741,948 nodes and 123,658 elements are used to discretize the 3D domain.

Based on previous modeling studies (AUG 2009; 2010; Moeck et al. 2017a) boundary conditions are set in the two aforementioned hydrogeologically relevant units: The Quaternary sand and gravel, and the Upper Muschelkalk aquifers (Moeck et al. 2016). For the Quaternary aquifer, a constant head boundary condition is set at the southern edge of the model domain between two piezometers (Figure 2). Furthermore, flux boundary conditions are applied at the western and eastern model domain boundaries which represent inflow from the valley border. Inflow rates for these boundaries were taken from previous modeling studies at the study site (AUG 2009; 2010).

For the bedrock aquifer, flux boundary conditions are set along the lateral boundaries in the south and east (Figure 2). These flux boundary conditions are applied to represent inflow from the regional flow path in the fractured and likely karstified limestone.

The two rivers, Rhine (north) and Birs (west), are implemented as Cauchy boundary conditions. A river-aquifer fluid transfer rate of $10 \mathrm{~d}^{-1}$ was assumed for the river Rhine (AUG 
2009; 2010), whereas a rate of $35 \mathrm{~d}^{-1}$ was set for the river Birs (AUG 2009; 2010). The transfer rate is a conductance term defined by the ratio between hydraulic conductivity of a semi-permeable leakage layer and its thickness.

Along the groundwater recharge channels and ponds at the top of the model domain (Figure 1c), a total recharge rate of $95,000 \mathrm{~m}^{3} \mathrm{~d}^{-1}\left(8.6 \mathrm{~m} \mathrm{~d}^{-1}\right.$ across a surface area of roughly 11,050 $\mathrm{m}^{2}$ ) is applied which strongly controls the water budget in the study area. This groundwater recharge rate is distributed along 13 sections of channels and ponds based on the abovedescribed mass balance calculation (Moeck et al. 2017b), where the highest infiltration occurs close to the eastern injection point and only about $25 \%$ of the injected water infiltrates at the west end of the channels. As noted by Moeck et al. (2017b), the observed infiltration rates were relatively stable in time and space, therefore a steady-state recharge rate was assumed in the model.

Over the rest of the top surface, an average natural recharge rate of $423 \mathrm{~mm} \mathrm{yr}^{-1}\left(0.001 \mathrm{~m} \mathrm{~d}^{-1}\right)$ was applied (estimated by AUG 2010). Paved urban areas were assigned a lower groundwater recharge rate of $171 \mathrm{~mm} \mathrm{yr}^{-1}$ (AUG 2010), while all remaining boundaries were set with noflow conditions, including the model base. In total, 76 pumping wells are included, of which 33 wells are set into the sand-gravel aquifer for drinking water extraction (with a total pumping rate of $\left.45,000 \mathrm{~m}^{3} \mathrm{~d}^{-1}\right)$.

\section{Model calibration}

The steady-state groundwater model was calibrated to head values from 116 monitoring wells (Figure 1c) using the inverse parameter estimation code PEST (Doherty 2011). The calibration period represents time-averaged hydrogeological conditions. Instead of using absolute head values, calculated lateral head differences were applied in the model calibration. Due to uncertain model boundary conditions and model simplifications, some model parameters will most likely be assigned values that compensate for structural defects in 
the model. Using head differences allows better estimates of the $K$, whereas absolute values might be biased by incorrectly chosen model boundaries (Doherty and Welter 2010).

The spatial variations in $K$ are estimated by using a pilot point approach for each of the model layers. An anisotropy ratio between the horizontal direction (assuming $K_{x x}=K_{y y}$ ) and the vertical direction $\left(K_{z z}=K_{x x} / 10\right)$ is applied. The pilot point method is an alternative to the zonation approach and introduces great flexibility to calibrate heterogeneous systems without neglecting expert knowledge (Doherty 2003). Interpolation of the model parameters between the pilot points (starting from initial values, Table 1) was based on Kriging within each layer with a reasonable exponential variogram. Due to the limited amount of data (e.g. with only discrete $K$ values estimated from pumping or slug tests) the variogram is uncertain, which is a common problem in hydrogeology field investigations (Schöniger et al. 2015). However, when a large number of pilot points are used, uncertainty in the description of the variogram does not typically have a strong effect. Overall, with an increasing number of pilot points, the variogram is less important (Doherty 2015) and only a reasonable estimate is required. Subsequently, the model is run with the given parameter field, and an objective target function $\emptyset$ is calculated by comparing measured and simulated observations (Equation 1):

$\emptyset=\sum_{i=1}^{116} w_{i}\left(h_{o b s, i}-h_{s i m, i}\right)^{2}$

where $w$ denotes the weight assigned to the piezometric head $(h)$, and the indices $o b s$ and sim represent observed and simulated head differences for the 116 monitoring wells, respectively. PEST modifies the pilot point values to minimize the objective target function in the subsequent calibration steps. In this study, equal weights are used for all monitoring wells. Alternatively, higher weights for more trustworthy and informative observations could be used to include expert knowledge (Poeter and Hill 1997; Fienen 2013), but which would add user subjectivity in the optimization approach (Rosolem et al. 2012). Although the 
combination of "hard" data like the observations, and "soft" data such as different weighting strategies for these observations, can lead to a more robust and complete analysis, we have chosen equal weights because we could not identify observations which were more trustworthy than others.

For each of the six model layers, 60 pilot points are set within the model domain (Figure 3 ). The pilot points are distributed uniformly in the east-west direction but unevenly in the southnorth direction where they are spaced more tightly in the vicinity of the artificial infiltration zones and drinking water wells. Apart from having more observation wells in these locations, a higher density of pilot points is useful here because the artificial infiltration and pumping wells lead to steeper variability in hydraulic gradients and there is a higher spatial density of information from the observation wells. Moreover, pilot points were strategically placed between head measurements along the direction of the main groundwater flow path north towards the Rhine River (as suggested by Christensen and Doherty, 2008, Klaas and Imteaz 2017). The chosen pilot point density allows exploring the required subsurface heterogeneity which is needed to provide suitable model fits to the field observations but still allows a reasonable computational time considering the complexity of such an inverse parameter estimation exercise. Furthermore, singular value decomposition (SVD) and the Tikhonov regularization approach are applied in the calibration process to ensure numerical stability, and prior knowledge from the geological model is included to ensure the parameter fields are reasonable from a geological perspective.

Subsequently, the pilot point method is combined with the NSMC analysis (Tonkin and Doherty 2009) to provide spatial variations in $K$. Here, 1,000 different parameter sets are generated with random log normal parameter distributions based on the provided upper and lower parameter range (Table 1). These parameter sets are then modified through null-space projections adapted from the base model. Based on the applied SVD in the inverse parameter 
estimation problem, PEST decomposes the parameter space into two orthogonal subspaces (solution- and null-space). The solution-space represents parameter combinations that are able to be estimated based on the current field dataset used for the calibration. Parameter combinations that cannot be estimated based on the current dataset are considered as spanning the null-space. Then, each random parameter set is projected onto the calibration null-space and the solution-space component of this field is removed, and replaced with the calibrated parameter field from the base model. For a linear model, the resulting null-space projected parameter field would calibrate the model. However, groundwater models are typically nonlinear and therefore the null-space projected stochastic parameter field requires recalibration which was thus carried out in this case for the 1,000 parameter sets. Here, only solution-space components of the null-space projected stochastic parameter field are varied in the recalibration which reduces the computational burden. Finally, the obtained objective target function $(\varnothing)$ is compared to the desired objective target function, which includes the expected level of model to measurement error and an assumed level of structural noise (model imperfection). Only $\emptyset$ values equal to or less than the desired objective target function threshold are accepted for further analysis. The parameter sets leading to larger values in the resulting $\emptyset$ are omitted. Certainly, the chosen threshold value for the objective target function is somewhat subjective but includes expert knowledge for the study site which also incorporates the expected imprecision in the boundary and operating conditions. A maximum of two iterations is applied in the recalibration exercise to further reduce the computational demand. If the desired minimum of the objective target function $\emptyset$ has not been reached within the two optimization iterations, PEST abandons the recalibration process and subsequently moves on to the next initial model parameter set. For the first optimization iteration, derivatives are already available from the base model parameter derivatives. This reuse of the parameter derivatives also reduces the computational burden of the parameter field recalibration. Since this is not the case for the second or additional iterations, the modeler has 
to decide whether it is more efficient to allow the possibility of yet another optimization iteration, or whether the optimization process should be abandoned in favor of beginning another PEST run based on another random parameter set for which the objective function target may more easily be met. In this study, we decided to use just two optimization iterations to reduce the computational burden. Increasing the number of optimization iterations may lead to a larger number of accepted $K$ fields but would also increase the computational demand. A more comprehensive description of the NSMC analysis method can be found elsewhere (Herckenrath et al. 2011; Sepulveda and Doherty 2015; Tonkin and Doherty 2009, among others).

Table 1: Hydraulic conductivity parameter range (lower to upper limits) used in the pilot point calibration. The initial value is based on the estimated K from a zonation model for the study area (Moeck et al. 2017a).

\section{$K\left[\mathbf{m ~ d}^{-1}\right]$}

\begin{tabular}{cccc} 
Geological zone & Initial & Lower limit & Upper \\
& value & & limit \\
\hline $\begin{array}{c}\text { Quaternary sand-gravel aquifer } \\
\text { Keuper and Jurassic strata }\end{array}$ & 216.0 & 43.2 & 864.0 \\
$\begin{array}{c}\text { Upper Muschelkalk aquifer } \\
\text { Sulphate zone (Middle } \\
\text { Muschelkalk) }\end{array}$ & 10.37 & $8.64 \mathrm{E}-05$ & 0.43 \\
Flexure zone & $3.72 \mathrm{E}-02$ & $8.64 \mathrm{E}-08$ & $8.64 \mathrm{E}-04$ \\
& 4.06 & $8.64 \mathrm{E}-02$ & 432.0 \\
\hline
\end{tabular}

\section{Model predictions}

To delineate the most likely source area of the pumped or sampled water at the wells and to identify the most likely occurring flow path, a PT technique was applied. At the 33 pumping wells, the objective is to ensure that only artificially infiltrated surface water is extracted and 
to confirm that regional groundwater up-gradient of the infiltration gallery, which is potentially contaminated, is not migrating towards the pumping well gallery. To improve upon classical PT, we used all accepted model parameter sets from the NSMC approach to account for uncertainty in the calibration of the $K$ field. In the steady-state model, we used the PT technique incorporated within the user interface of the Feflow code which tracks particles using a fourth-order Runge-Kutta approximation. For all accepted model parameter sets (which met the minimization criteria for the objective target function $\emptyset$, Eq.1), 3D backward tracking is carried out from each of the 33 pumping wells used for drinking water supply, eight of the monitoring wells in the sand aquifer, and six of the monitoring wells in the bedrock aquifer. Since the field monitoring wells have detectable concentrations of chlorinated solvents (see for example, Moeck et al. 2016) backward particle tracking would allow determining the source area of the sampled water. The different number of selected piezometers in the bedrock vs. the sand aquifer is related to differences in the contaminant concentrations and to the spatial distribution of the piezometers in each unit. The particle release points for the backward tracking are linked to the monitoring well screen positions. Similar to Alberti et al. (2018), we compute the number of particles crossing the model cells based on all model simulations and generate spatial pathline density distributions ( $\%$ of the particles passing each cell relative to total number) within the two model layers. Particle travel distances and travel times (residence time) along pathlines through the model cells were not considered but could be included if such information is important for the study objective. For areas with high pathline density distributions (high percentage of particles passing through the model cell), the simulated particle tracks can be used to delineate the most likely source area of the pumped or sampled water at the wells, as well as identifying the corresponding flow paths. However, since all realizations are equally likely, areas with lower pathline density distributions must still be considered as a possible system state. The 
uncertainty in the simulated flow directions (reflected in the pathline density map) is controlled by the spatial variations in $K$.

In addition to including uncertainty in the hydraulic conductivity, a linear uncertainty approach is applied to investigate the importance of the chosen boundary conditions for flow predictions. Since calibrated data are not required for this analysis, the sensitivity of model parameters to the corresponding observations used in the calibration dataset can be easily assessed.

The uncertainty reduction from calibration for three pumping well locations (Figure 3) is evaluated using particle tracking; specifically, the path length used as an indicator for the source area of the pumped water. The wells used for the predictions are located at the western (P1) and eastern position as well as relatively central (P3) among the 33 pumping wells. These locations were chosen to represent the spatial variability of the well gallery, which might be differently affected by the applied boundary conditions. Although this analysis focuses on only three predictions of interest to provide a specific example, the method could be applied also to any other model prediction. Apart from the hydraulic conductivity values, model boundary values and multipliers were additionally used to take the effect of uncertain boundary conditions into account (Table 2).

Table 2: Summary of prior parameter distribution. The fifth column shows the $\log _{10}$ of each parameter representing the authors' best estimate of a parameter's standard deviation.

\begin{tabular}{|c|c|c|c|c|c|}
\hline Parameter & Location/Unit & Abbreviation & Transform & $\begin{array}{c}\text { Base } \\
\text { parameter } \\
\left(\log _{10}\right)\end{array}$ & $\begin{array}{c}\sigma \\
(\log 10)\end{array}$ \\
\hline \multirow{3}{*}{$\begin{array}{l}\text { hydraulic conductivity } \\
\qquad\left(\mathrm{m} \mathrm{d}^{-1}\right)\end{array}$} & $\begin{array}{l}\text { Quaternary sand - } \\
\text { gravel aquifer }\end{array}$ & K_q & $\log _{10}$ & 2.33 & 0.50 \\
\hline & $\begin{array}{l}\text { Keuper and } \\
\text { Jurassic strata } \\
\text { Upper }\end{array}$ & K_kj & $\log _{10}$ & -4.06 & 0.50 \\
\hline & $\begin{array}{l}\text { Muschelkalk } \\
\text { aquifer }\end{array}$ & K_m & $\log _{10}$ & 1.02 & 0.30 \\
\hline
\end{tabular}




\begin{tabular}{|c|c|c|c|c|c|}
\hline & $\begin{array}{l}\text { Sulphate zone } \\
\text { (Middle } \\
\text { Muschelkalk) }\end{array}$ & K_s & $\log _{10}$ & -1.43 & 1.25 \\
\hline & Flexure zone & $\mathrm{K} \_f$ & $\log _{10}$ & 0.61 & 1.25 \\
\hline $\begin{array}{l}\text { artificial infiltration } \\
\text { multiplier (-) }\end{array}$ & $\begin{array}{l}\text { same multiplier } \\
\text { for all channels } \\
\text { and ponds } \\
\text { same multiplier }\end{array}$ & M_ai & $\log _{10}$ & 0.00 & 0.20 \\
\hline recharge multiplier (-) & $\begin{array}{l}\text { for the natural and } \\
\text { paved surface }\end{array}$ & M_r & $\log _{10}$ & 0.00 & 0.02 \\
\hline $\begin{array}{l}\text { pumping well } \\
\text { multiplier (-) }\end{array}$ & $\begin{array}{l}\text { same multiplier } \\
\text { for drinking water } \\
\text { wells }\end{array}$ & M_p & $\log _{10}$ & 0.00 & 0.20 \\
\hline \multirow{2}{*}{$\begin{array}{c}\text { Quarternary flux } \\
\text { boundary multiplier (-) }\end{array}$} & $\begin{array}{c}\text { Quarternary - } \\
\text { West }\end{array}$ & M_qw & $\log _{10}$ & 0.00 & 0.02 \\
\hline & Quarternary - East & M_qe & $\log _{10}$ & 0.00 & 0.02 \\
\hline $\begin{array}{l}\text { constant head } \\
\text { boundary multiplier (-) }\end{array}$ & $\begin{array}{l}\text { Quarternary - } \\
\text { South }\end{array}$ & M_qs & $\log _{10}$ & 0.00 & 0.02 \\
\hline \multirow{2}{*}{$\begin{array}{c}\text { flux boundary } \\
\text { multiplier (-) }\end{array}$} & Bedrock - East & M_be & $\log _{10}$ & 0.00 & 0.02 \\
\hline & Bedrock - South & M_bs & $\log _{10}$ & 0.00 & 0.02 \\
\hline \multirow{2}{*}{$\begin{array}{l}\text { River-aquifer transfer } \\
\text { rate }\left(\mathrm{d}^{-1}\right)\end{array}$} & Rhine & R_r & $\log _{10}$ & 1.00 & 0.30 \\
\hline & Birs & R_b & $\log _{10}$ & 1.54 & 0.30 \\
\hline
\end{tabular}

\section{Results}

\section{Model calibration}

In total, $88 \%$ of the generated parameter sets led to a calibrated model with null-space projection and subsequently, to a recalibration. This percentage could have been higher if more than two iterations had been allowed. For the remaining uncertainty analysis, only the parameter sets that led to a sufficiently low target function during the calibration ( $88 \%$; i.e. 880 parameter sets) were considered.

Figure 4 shows the scatter plot between simulated (x-axis) and observed (y-axis) groundwater heads for the 116 monitoring wells. The variations in the model fit for each piezometer due to different realizations of subsurface heterogeneity are shown within the lower and upper range (maximum and minimum simulated values displayed as vertical bars), while the ensemble means are shown as black data points. Overall, a good fit is achieved between the simulated 
and observed heads, with a mean correlation of 0.93 and only a small systematic overestimation. The residuals ( $r$ ) for the simulated groundwater heads at the piezometers can show local errors of $>1 \mathrm{~m}$, however most of the residuals are within the range $0.0<|\mathrm{r}|<0.5 \mathrm{~m}$. Here, in addition to only a fraction of the real subsurface heterogeneity being represented, additional local misfits may arise from various model simplifications.

\section{Spatial distribution of subsurface parameters}

During the calibration process, mathematical regularization is applied, and $K$ distributions are tied to the available prior geological knowledge. Figure 5 shows an example of the $K$ distribution for the bedrock aquifer for four randomly chosen parameter realizations out of the available 880 . The four randomly chosen $K$ fields based on the pilot point approach show variability in the $K$ pattern, however the general distribution of the geological units is reasonably similar to those of the geological model (see Figure 1 and 2). In the northern and the western parts of the model domain, for example, low $K$ values are present, corresponding to the sulphate zone and the tertiary sediments. Near the centre of the model domain, as well as in the eastern part, $K$ values are higher, which represent the Upper Muschelkalk. Although the general distribution of the geological units between the simulated fields and the geological model is quite similar, some differences can be noted. For example, the units in the geological model mainly follow a southwest to northeast trend whereas the simulated fields look more continuous in the southeast to northwest orientation.

Figure 6 shows the interpolated map of the standard deviation of $\log _{10} \mathrm{~K}$, based on variations in the pilot points for the different model realizations. A value of 1 represents a variation of one order of magnitude in the $K$ value. The maps are shown for the sand-gravel aquifer and the bedrock aquifer. Blue colors represent areas of low variation in the model parameters, corresponding to areas where narrow boundaries exist, whereas red colors indicate areas of larger variations in the estimated model parameters. 
For the sand-gravel aquifer, variations in $K$ values are lowest in the middle part of the model domain where most of the piezometers used for the calibration are available. $K$ values show greater variability in the north-east and in the south-west where fewer observations exist. At these locations, the information content of the head observations probably does not sufficiently constrain the parameter estimation approach.

For the bedrock aquifer, a larger variability in the $K$ values can be seen where the Upper Muschelkalk and Flexur zone is expected (see Figure 1). As aforementioned, the Upper Muschelkalk is a fractured and likely karstified limestone aquifer for which investigations have shown that the hydraulic conductivity can vary by more than one order of magnitude (Gürler et al. 1987; Spottke et al. 2005). Moreover, the $K$ of the fractured flexure zone is also unknown and is likely spatially variable. This spatial variability, paired with only a small number of observations, likely leads to various possible model parameter combinations.

Overall, the $K$ pattern (Figure 5) shows that the areas of greatest subsurface heterogeneity are correlated with areas of more intense observation data, while the standard deviation map (Figure 6) shows that areas with the highest degree of variability (and therefore uncertainty), corresponds to areas where there is a lack of data to constrain the model parameters. Areas of highest uncertainty (e.g., in the southern portion of the bedrock aquifer, Figure 6) contain relatively smooth $K$-distributions (Figure 5). It seems that areas lacking local observational data may appear more homogeneous, yet are still more uncertain because of this same lack of data.

\section{Backward particle tracking: Influence of subsurface heterogeneity on groundwater flow directions}

For the 33 drinking water wells, the pathline density distributions in Figure 7 show that most pumped water is obtained from the infiltration channels and ponds. This is in fact the desired outcome of the management plan which ensures a secure water supply. The results further 
suggest that regional groundwater from outside of the study area, which is potentially contaminated, is not migrating towards the pumping well gallery. For only a few wells located near the central part of the gallery, some pumped water might originate from a regional groundwater component. Since all realizations are equally likely, the outcome that some pathlines extend beyond the infiltration channels must also be considered as a possible system state and not as an unlikely result.

In fact, mixing between young artificially-infiltrated water and regional groundwater has been observed in these central locations (Moeck et al. 2017c). The fact that only a few realizations resulted in particle tracks that support the field observations highlights the need for a rigorous uncertainty assessment. This becomes clear when the pathline spreading distributions are compared to the PT simulation based on a single randomly-chosen parameter realization. Considering only a single flow simulation, a smaller extent of the capture zone is obtained and the pathlines do not extend beyond the infiltration channels (dashed lines in Figure 7a). Although single flow simulations with PT might provide some useful insight and can be used as an initial screening tool, they are not comprehensive enough to be used for decisionmaking. For locations of high uncertainty, the limited number of available observations does not sufficiently constrain the model parameters and therefore these areas indicate locations of important data gaps, and where additional observations should be obtained to better constrain the estimated model parameters.

For the monitoring wells in the sand-gravel aquifer, important trends can be observed in the pathline density distribution of Figure 7. For example, in the vicinity the artificial infiltration channels and ponds, including the nearby drinking water and monitoring wells, the spreading of pathlines is less than for locations further south. In the south of the study area, pathlines indicate that the monitoring wells here are most likely intercepting groundwater from a regional flow system. Although the $K$ pattern (Figure 5) shows that the subsurface heterogeneity is greater near the drinking water wells, driven by more intense observation data, the pathline 
spreading is less. In contrast, the more pronounced pathline spreading in the south corresponds to the highest variability in the realizations (Figure 6), and where no observation data exist to constrain the model parameters. The monitoring wells in the western part also show pathline spreading, caused by the aforementioned unequal infiltration distribution (Moeck et al. 2017b) and again where there is less observation data to constrain the model parameters.

In the bedrock aquifer, the effect of artificial infiltration can still be observed at the monitoring wells in the vicinity of the infiltration channels and ponds. Very similar behavior can be seen in the sand-gravel aquifer.

\section{Linear uncertainty of model parameters and boundary conditions}

Using the linear uncertainty analysis, we evaluate which model inputs (hydraulic conductivity values or boundary conditions) have the greatest effect on uncertainty reduction in the three predictions of interest (see also Figure 3). As shown in Figure 8, the predictions are not equally informed by the calibration process using uncertainty reduction as a metric. The greatest reduction is obtained for the western and central predictions where the eastern prediction shows the lowest reduction in uncertainty. Overall, the reduction in uncertainty is relatively limited, indicating that the current dataset does not provide sufficient information for the inverse parameter estimation. Adding more and different observations would likely help to better constrain the parameter estimation (Anderson 2005; Anderson et al. 2015; Bravo et al. 2002; Colombani et al. 2015; Meyer et al. 2018).

To better assess the effect of the hydraulic parameters and boundary conditions, we also evaluated which groupings of parameters and boundary conditions reduce the uncertainty most. In Figure 9 the hydraulic parameters (abbreviated with $\mathrm{K}_{-}^{*}$ ), river boundary conditions (abbreviated with R-*) and boundary multiplier (abbreviated with M-*) (see Table 2) are shown for the three predictions. Note that a $100 \%$ variance reduction in Figure 9 indicates the maximum uncertainty reduction (shown in Figure 8). As shown in Figure 9, the hydraulic conductivity field (K_q) in the Quaternary sand-gravel aquifer (top layer) exhibits the most 
significant uncertainty reduction for all three predictions (recall that the wells used for the predictions are located in this aquifer). The aquifer properties in the remaining hydrogeological units are relatively less important for the particle tracking path lengths. Only the hydraulic conductivity field of the Muschelkalk aquifer seems to have a slightly greater importance, likely due to the possible upwelling of regional Muschelkalk groundwater into the Quaternary aquifer (Moeck et al. 2016). Another significant observation in Figure 9 is the importance of the artificial recharge rates (M_ai; multiplier). It is known that the extracted drinking water is dominated by artificially-infiltrated groundwater originating from the local infiltration canals (Moeck et al. 2017b). Since a change in the infiltration rate can control the flow field in the vicinity of the wells, it will therefore have a significant influence on the predictions. Interestingly, the importance of the artificial recharge rate is greater for the central travel path prediction than for the western or eastern predictions. A similar trend can be observed by considering the pumping well boundary conditions $\left(\mathrm{M} \_\right.$p). The artificial infiltration and pumping rate boundary conditions are more important in the central location whereas for the western and eastern prediction the flux boundary conditions (M_qe and M_qe) have an increasingly important role. All other boundary conditions seem to be less important for the chosen three predictions.

\section{Discussion}

\section{NSMC analysis with pilot point approach}

Using the NSMC analysis with a pilot point approach has led to various possible descriptions of the Basel-site $K$ field that provide similar fits to field observations. Each $K$ field is also geologically reasonable and can therefore be considered as one possible picture of the hydrogeological system. At the Basel site, the subsurface uncertainty strongly influences the flow gradients and spreading of the pathlines as reflected in the pathline density distributions. This finding can have significant implications for field work and water management strategies 
(Devlin and Schillig 2017; McKenna and Wahi 2006) as well as for transport of pollutants in the subsurface (Fiori et al. 2016, Frind and Molson 2018). The NSMC analysis can be combined with various models and model predictions (e.g. Tonkin and Doherty 2009, Moeck et al. 2018) and does not necessarily include PT as applied in this study.

\section{Study area}

At our study site, the results suggest that the pumped water is most likely artificiallyinfiltrated groundwater originating from the channel and ponds of the infiltration system, which is consistent with previous field studies (e.g. Moeck et al. 2016, Moeck et al. 2017b). Only the central part of the pumping well gallery might be extracting regional groundwater. Although the simulations show that the probability would be low, mixing between young artificially-infiltrated water and regional groundwater has been observed in these central locations (Moeck et al., 2017c). The need for an uncertainty assessment is highlighted by the fact that only a few realizations resulted in particle tracks that supported the field observations (i.e., mixing between young artificially-infiltrated water and regional groundwater flowing towards the pumping wells).

\section{Limitations}

\section{Steady-state model}

The above interpretation for the study area might be limited because only time-averaged boundary conditions were used in the steady-state flow model. Rayne et al. (2014) claim that groundwater flow, mass transport, and well capture zones can be better represented under transient conditions. Storage coefficients and other dynamic parameters such as infiltration and exfiltration rates along the rivers also do not appear in the governing steady-state flow equation and must therefore be adjusted in a subsequent transient model calibration. Moreover, using temporal observations in the calibration with, for example, head variations due to pumping and infiltration, may reduce uncertainty. Nevertheless, a steady-state flow 
solution with time-averaged boundary conditions can be seen as a conservative analysis of flow and transport processes representing long-term average conditions of the system (Alberti et al. 2018). Anderson et al. (2015) noticed that a steady-state model is often sufficient if the modeling task mainly requires information on the long-term effects of, for example, pumping rates.

\section{Equivalent Porous Medium approach}

Another important simplification in this study is the use of an Equivalent Porous Medium (EPM) approach for fractured and deformed geological units of the bedrock. The possible fast flow component in the fractures cannot be accurately reproduced with an EPM approach and thus interactions between the fractures and surrounding matrix are neglected or simplified (Chapman et al. 2014). PT pathlines, and the local velocities controlling the particle tracks, are basically averaged EPM velocities. In terms of physical transport processes, these particle tracks are suitable for representing advection, but not for transverse spreading and matrix diffusion. Neglecting dispersion can have important implications for the assessment of capture zones and well vulnerability (Frind and Molson 2018). As demonstrated by Allen et al. (2017), the hydrogeological conditions of fractured bedrock aquifers can create wide capture zones and short travel times to wells making them more vulnerable to contamination. Although a 3D DFN approach would be most rigorous, in that the fractures and the porous medium are represented explicitly, DFN models are typically restricted due the computational demand and unknown fracture distribution, as in the case for our study site. Moreover, PT may not work well because particles tend to get trapped in the fractures, although new particle tracking approaches have been developed to overcome this problem (Roubinet et al. 2010; Willmann et al. 2013). Thus, the DFN method can be considered impractical for real systems (Chapman et al. 2012; Chapman et al. 2014; Frind and Molson 2018). 
As an alternative for all types of media, one could also use the capture probability (CP) approach, which is based on the backward advective-dispersive transport equation and uses macrodispersion to account for uncertainty (Frind and Molson 2018, Neupauer and Wilson 2001, Molson and Frind 2012). Hybrid EPM-DFN approaches may also have the potential to realistically represent matrix and fracture flow and transport (Chapman et al. 2014). An EPM approach was chosen in this study since the fracture spacing scale is assumed small relative to the simulation domain scale, and we thus assume that the fractured geological units will act as a porous system. We acknowledge, however, that this model simplification can potentially lead to a smaller extent of the capture zone, as perhaps suggested in Figure 7 where the pathline density distribution is about the same for both the sand-gravel and bedrock aquifers.

\section{Discretization and velocity interpolation}

Our vertical discretization and the type of spatial interpolation of velocities may further limit reliability of the particle tracks. As noticed by Zheng (1994), weak sinks and sources (e.g. extraction or injection wells) and varying vertical cell dimensions can lead to less reliable particle tracks. This problem can be mitigated with increased spatial discretization, but with the cost of longer computational time (Visser et al. 2009). Additionally, difficulties in using PT can occur at interfaces between formations with high permeability contrasts, even when more accurate velocity fields are used (Sbai 2018). In particular, reliable PT pathlines can be difficult to simulate in layered aquifer systems with a high degree of vertical communication (Frind et al. 2002; Molson and Frind 2012). Numerical PT error was minimized in our study, by using a finer discretization at sinks (e.g., pumping wells) and sources (e.g., infiltration channels and ponds and rivers), as well as within the assumed fracture zones.

\section{Selected model, boundary conditions and delineation method}

Chow et al. (2016) noted that the delineation of source zones and capture zones can be affected by the choice of groundwater model and by the delineation method. They 
demonstrated that different models can be calibrated equally well, but these models and delineation methods, such as reverse PT and backward transport, can produce different capture zones. PT in complex groundwater flow systems also requires subjective judgment in the delineation of capture zones. As an alternative, backward advective-dispersive transport with CP can be used which provides probability intervals for capture zones by taking uncertainty into account (Chow et al. 2016). As stated by Frind and Molson (2018), however, both methods, backward PT within a Monte- Carlo framework and backward advectivedispersive transport are appropriate methods for capture zone delineation in heterogeneous media under uncertainty. Both are based on sound science and will, if applied correctly, produce reliable well capture zones and can identify contaminant source locations and pathways (assuming that the conceptual model and selected boundaries are correct). Rojas et al. (2008) shows that conceptual model uncertainty can contribute up to $30 \%$ of the total uncertainty. This structural noise, being the imperfect or uncertain nature of a numerical model as a simulator of reality, can contribute significantly to model-to-measurement misfit and predictive uncertainty (White et al. 2016). Model simplification can further increase the predictive uncertainty, even though the historical observations are well-matched (Cooley and Christensen 2006; Crosbie et al. 2011; Doherty and Christensen 2011; Gallagher and Doherty 2007; Moeck et al. 2018). Unfortunately, in real-world modeling, strategies for filtering out structural noise are always heuristic (Doherty and Welter 2010). Several different filter strategies have been suggested in the literature which can be applied individually or in combination. One possible way to identify structural noise could be the formulation of a multicomponent objective function (Wang and Brubaker 2015). Moreover, vertical, lateral and/or temporal head differences could be used in the model calibration (Doherty and Welter 2010). This strategy allows a better estimate of vertical conductance, horizontal transmissivity and/or the storage coefficient because absolute heads, which might be biased by incorrectly chosen model boundaries, are not used (Doherty and Welter 2010). A multi-model (Sousa et 
al. 2013) and multi-method (Chow et al. 2016) approach could be used to explore uncertainty in the model conceptualization and chosen method. However, in practice, multi-model analyses might not always be practical or computationally feasible (Chow et al. 2016). Doherty and Welter (2010) noticed that the only conclusion that is universally applicable in this regard is to ignore structural noise, or treating their manifestations as an additive term to measurement noise under the assumption that the statistical properties of these manifestations are similar to those of measurement noise.

In order to reduce the effect of uncertain boundary conditions and model simplification, we used lateral head differences in the model calibration to avoid absolute values, which can be influenced by model imperfections. Moreover, the desired objective target function includes two terms, the expected level of model to measurement error and an assumed level of structural noise to avoid overfitting. For future applications of this model, the calibration and prediction might be further improved by using a multicomponent objective function including geochemical data.

As demonstrated herein, additional sources of uncertainty exist beyond the hydraulic conductivity. Uncertainty of capture zone geometry due solely to the hydraulic conductivity field may indeed be eclipsed by uncertainty due to poorly known boundary conditions. Furthermore, if boundary condition uncertainty is the main contributor to predictive uncertainty, the hydraulic conductivity field estimates will very likely compensate for incorrect boundary conditions (Doherty and Welter 2010, Peeters and Turnadge 2019). Based on our linear uncertainty analysis, we observed that the current dataset does not provide sufficient information for the inverse parameter estimation, although it is clear that the hydraulic conductivity fields of the Quaternary and Muschelkalk aquifers were (most) important for the predictions. Boundary conditions, notably the artificial recharge rate and, to a slightly less extent the pumping wells, can also significantly affect the pathline predictions. This analysis can help guide parameterization design and objective function formulation, and 
can help optimize collection of new data (White et al. 2016). Therefore, explicitly accounting for uncertainty in the boundary conditions is a necessity rather than a choice. In particular, when future boundary conditions are significantly uncertain, it may be more important to focus on these conditions rather than focusing on traditional calibration approaches using static properties (White et al. 2016).

\section{Observation type and measurement error}

In addition to the aforementioned structural error (Doherty and Welter 2010; Ferré 2017), measurement type and noise can also influence the calibrated heterogeneity in the $K$ field (Doherty 2003; Poeter and Hill 1997; among others) and consequently different pathline distributions can be obtained. Apart from measured hydraulic heads, other observations such as temperature, solute concentrations, and flux observations could also be used as a means to constrain the estimates of groundwater model parameters (Anderson 2005; Anderson et al. 2015; Bravo et al. 2002; Colombani et al. 2015; Meyer et al. 2018). It can be speculated that adding more and different observations will help to better constrain the parameter estimation. When observations are of different types, weights are vital in setting the relative importance of each measurement type in the overall parameter estimation process. Different weighting strategies could be applied with higher weights for more trustworthy and informative observations in the model calibration (Poeter and Hill 1997; Fienen 2013). The combination of "hard" data like the observations and "soft" data such as different weighting strategies for these observations, can lead to a more robust and complete analysis.

\section{Benefits of the PT-NSMC approach}

Standard PT approaches without Monte-Carlo will not represent the underlying subsurface uncertainty and will always provide smaller well capture zones. Source locations and flow pathways will also be more poorly constrained compared to a PT-Monte-Carlo based framework (Enzenhoefer et al. 2014). While PT based on a single flow simulation can be used 
as an initial screening tool, our study, together with previous work (Alberti et al. 2018;

Enzenhoefer et al. 2014; Frind and Molson 2018; Herckenrath et al. 2011; Meyer et al. 2014; Tonkin and Doherty 2009; among others), highlights that model results and hence water resource management decisions should not be based on only one model realization; rather, an uncertainty analysis should be carried out to provide simulations within the range of all likely system states, including uncertainties in the hydraulic K distribution, which can then be used to identify potential source zones and pathways to water supply wells. Pathline density distributions, here created following a simple post-processing step applied to the flow field, can provide probability information maps beyond classical deterministic PT approaches. These maps provide an easy to understand decision-support tool which provides the required knowledge for developing improved risk-based management schemes.

\section{Summary and Conclusions}

A three-dimensional groundwater flow model is developed for a study area in Switzerland, where drinking-water production wells are close to several landfills and industrial areas. The model is calibrated using a parameter estimation approach, which is based on multiple equally-calibrated realizations of the $K$ field, generated using a NSMC approach. Spatial variations in $K$ are obtained by using the pilot point methodology. Backward PT is applied to each calibrated model, and the density of the resulting particle path distribution is used to illustrate the range of potential source areas for the pumping wells, and to identify groundwater pathways which intersect the monitoring wells. Moreover, the uncertainty in the boundary conditions is assessed with a linear uncertainty analysis.

The applied NSMC methodology leads to various possible descriptions of the $K$ field that provide similar fits to the field observations. Moreover, since each field is also geologically reasonable, they each provide an equally possible description of the subsurface. Uncertainty 
in the description of the $K$ strongly influences the flow gradients and spreading of the pathlines. This spreading is most evident for model locations where the information content of the head observations does not sufficiently constrain the parameter estimation approach. This PT-NSMC approach provides simulations which can be used to identify potential source zones and pathways to water supply wells.

The hydraulic conductivity field of the main aquifer is shown to have the most important influence on the pathline predictions. As demonstrated with the linear uncertainty analysis, however, the artificial recharge rates and the pumping well conditions can also significantly affect the model predictions. Explicitly accounting for uncertainty in the boundary conditions is therefore a necessity rather than a choice.

The incorporation of uncertainty in the conceptual understanding at this critical drinking water supply site will lead to a more robust description of flow and transport processes and can assist in the design of field data acquisition campaigns. While single flow simulations with PT can be used as an initial screening tool to provide useful insight, they are incomplete, biased, and not comprehensive enough to be used for developing water-management strategies. Rather, an uncertainty analysis should be carried out to identify all possible system states and outcomes. The insights gained by the analysis approach presented herein can assist decision makers in understanding overall reliability of model predictions, can help identify specific strengths and weaknesses of a model, and underscores the important connection between data availability and model reliability (NGWA 2017).

\section{Acknowledgments}

The authors acknowledge the financial support of the Canton Basel-Landschaft, Switzerland, in the framework of the Regionale Wasserversorgung Basel-Landschaft 21 project, as well as the internal Eawag Discretionary Funding. Additional financial support was provided by the 
Swiss National Science Foundation (SNSF), Grant No. IZK0Z2_173680. We thank the group of Peter Huggenberger, Applied and Environmental Geology, University of Basel, who provided the geological model. We would also like to express our grateful thanks to Editor-inChief, Hendrik M. Haitjema, Executive Editor, Robert Schincariol, Associate Editor Michael Fienen and the two reviewers Emil Frind and Paul Martin for their time spent on the manuscript, for their effort and constructive comments and suggestions. The manuscript has benefited greatly from their comments.

\section{References}

Alberti, L., L. Colombo, and G. Formentin. 2018. Null-space Monte Carlo particle tracking to assess groundwater PCE (Tetrachloroethene) diffuse pollution in north-eastern Milan functional urban area. Science of the Total Environment 621: 326-339.

Allen, A. S., M. A. Borchardt, B. A. Kieke, K. E. Dunfield, and B. L.Parker. 2017. Virus occurrence in private and public wells in a fractured dolostone aquifer in Canada. Hydrogeology Journal, 25(4), 1117-1136.

Anderson, M. P. 2005. Heat as a ground water tracer. Groundwater, 43(6), 951-968.

Anderson, M.P., W.W. Woessner, and R.J. Hunt. 2015. Applied Groundwater Modeling: Simulation of Flow and Advective Transport, 2nd Edition. 1-564.

Asher, M.J., B.F.W. Croke, A.J. Jakeman, and L.J.M. Peeters. 2015. A review of surrogate models and their application to groundwater modeling. Water Resources Research 51 no. 8: 5957-5973.

Auckenthaler, A., D. Baenninger, A. Affolter, E. Zechner, and P. Huggenberger. 2010. Drinking water production close to contaminant sites: a case study from the region of Basel, Switzerland. GQ10: groundwater quality management in a rapidly changing world. . Proc. 7th International Groundwater Quality Conference held in Zurich, Switzerland, 13-18 June 2010 IAHS Publ. 342 167-170.

AUG, (Angewandte und Umweltgeologie der Universität Basel) 2009. Stationär kalibriertes Grundwassermodell Muttenz unteres Birstal: Berechnung geschichtlicher Szenarien zur Abschätzung der Schadstoffverteilung der Deponien in Muttenz [Steady-state calibrated groundwater model for Muttenz unteres Birstal: historical scenarios for the evaluation of contaminant distribution in the landfill in Muttenz]. Report BGA BL-155, AUG, Basel, Switzerland

AUG, (Angewandte und Umweltgeologie der Universität Basel) 2010. Grundwassermodell Unteres Birstal - Rhein - Muttenz: Evaluation der Zuströmbereiche der Trinkwasserfassungen Muttenz und Hardwasser AG [Groundwater model for Unteres Birstal - Rhein -Muttenz: evaluation of the inflow areas of drinking water sites Muttenz and Hardwasser AG]. Report BGA BL-155, $A U G$, Basel, Switzerland.

Baillieux, A., C. Moeck, P. Perrochet, and D. Hunkeler. 2015. Assessing groundwater quality trends in pumping wells using spatially varying transfer functions. Hydrogeology Journal 23 no. 7: 1449-1463.

Brauchler, R., J. Doetsch, P. Dietrich, and M. Sauter. 2012. Derivation of site-specific relationships between hydraulic parameters and p-wave velocities based on hydraulic and seismic tomography. Water Resources Research 48.

Bravo, H. R., F. Jiang, and R. J. Hunt. 2002. Using groundwater temperature data to constrain parameter estimation in a groundwater flow model of a wetland system. Water Resources Research, 38(8), 28-1. 
Brunner, P., Doherty, J., and C.T. Simmons. 2012. Uncertainty assessment and implications for data acquisition in support of integrated hydrologic models. Water Resources Research, 48(7).

Busse, J., F.L. Paillet, A. Hossack, D. Bringemeier, A. Scheuermann, and L. Li. 2016. Field performance of the heat pulse flow meter: Experiences and recommendations. Journal of Applied Geophysics 126: 158-171.

Butler, J.J. 2009. Pumping tests for aquifer evaluation-Time for a change? Groundwater 47 no. 5: 615617.

Butler, J.J., P. Dietrich, V. Wittig, and T. Christy. 2007. Characterizing hydraulic conductivity with the direct-push permeameter. Groundwater 45 no. 4: 409-419.

Butler, J.J., E.J. Garnett, and J.M. Healey. 2003. Analysis of slug tests in formations of high hydraulic conductivity. Groundwater 41 no. 5: 620-630.

Butler, J.J., C.D. McElwee, and G.C. Bohling. 1999. Pumping tests in networks of multilevel sampling wells: Motivation and methodology. Water Resources Research 35 no. 11: 3553-3560.

Butler, J.J., and X.Y. Zhan. 2004. Hydraulic tests in highly permeable aquifers. Water Resources Research 40 no. 12.

Butscher C, P. Huggenberger. 2007. Implications for karst hydrology from 3D geological modeling using the aquifer base gradient approach. Journal of Hydrology 342:184-198

Chapman, S. W., B. L. Parker, T. C. Sale, and L. A. Doner. 2012. Testing high resolution numerical models for analysis of contaminant storage and release from low permeability zones. Journal of Contaminant Hydrology, 136, 106-116.

Chapman, S.W., B.L. Parker, J.A. Cherry, P. Martin, D. Abbey, and S.D. McDonald. 2014. Combined EPM-DFN modeling approach for plumes in sedimentary bedrock aquifers. In DFNEInternational Conference on Discrete Fracture Network Engineering.

Chow, R., M.E. Frind, E.O. Frind, J.P. Jones, M.R. Sousa, D.L. Rudolph, J.W. Molson, and W. Nowak. 2016. Delineating baseflow contribution areas for streams - A model and methods comparison. Journal of Contaminant Hydrology 195: 11-22.

Christensen, S., and Doherty, J. 2008. Predictive error dependencies when using pilot points and singular value decomposition in groundwater model calibration. Advances in Water Resources, 31(4), 674-700.

Colombani, N., B. M. S. Giambastiani, and M. Mastrocicco. 2015. Combined use of heat and saline tracer to estimate aquifer properties in a forced gradient test. Journal of Hydrology, 525, 650657.

Cooley, R. L., and S. Christensen. 2006. Bias and uncertainty in regression-calibrated models of groundwater flow in heterogeneous media. Advances in Water Resources, 29(5), 639-656.

Crosbie, R. S., W. R. Dawes, S. P. Charles, F. S. Mpelasoka, S. Aryal, O. Barron, and G.K. Summerell. 2011. Differences in future recharge estimates due to GCMs, downscaling methods and hydrological models. Geophysical Research Letters, 38(11).

Dausman, A.M., J. Doherty, C.D. Langevin, and M.C. Sukop. 2010. Quantifying Data Worth Toward Reducing Predictive Uncertainty. Groundwater 48 no. 5: 729-740.

Demlie, M., S. Wohnlich, B. Gizaw, and W. Stichler. 2007. Groundwater recharge in the Akaki catchment, central Ethiopia: evidence from environmental isotopes (delta O-18, delta $\mathrm{H}-2$ and H-3) and chloride mass balance. Hydrological Processes 21 no. 6: 807-818.

Dentz, M., H. Kinzelbach, S. Attinger, and W. Kinzelbach. 2000. Temporal behaviour of a solute cloud in a heterogeneous porous medium: 1. Point-like injection. Water Resources Research 36, no. 12: 3591-3604.

DesRoches, A.J., and K.E. Butler. 2016. Monitoring and modelling of pumping-induced selfpotentials for transmissivity estimation within a heterogeneous confined aquifer. Geophysical Journal International 207 no. 3: 1722-1738.

Devlin, J.F. 2015. HydrogeoSieveXL: an Excel-based tool to estimate hydraulic conductivity from grain-size analysis. Hydrogeology Journal 23 no. 4: 837-844.

Devlin, J.F., and P.C. Schillig. 2017. HydrogeoEstimatorXL: an Excel-based tool for estimating hydraulic gradient magnitude and direction. Hydrogeology Journal 25 no. 3: 867-875.

Dogan, M., R.L. Van Dam, G.S. Liu, M.M. Meerschaert, J.J. Butler, G.C. Bohling, D.A. Benson, and D.W. Hyndman. 2014. Predicting flow and transport in highly heterogeneous alluvial aquifers. Geophysical Research Letters 41 no. 21: 7560-7565. 
Doherty, J. 2003. Ground water model calibration using pilot points and regularization. Groundwater 41 no. 2 : $170-177$.

Doherty, J., and D. Welter. 2010. A short exploration of structural noise. Water Resources Research, $46(5)$.

Doherty, J., and S. Christensen. 2011. Use of paired simple and complex models to reduce predictive bias and quantify uncertainty. Water Resources Research, 47(12).

Doherty, J. 2011. PEST Groundwater Data Utilities. Brisbane, Australia: Watermark Numerical Computing. Downloadable from www.pesthompage.org

Doherty, J. 2015. Calibration and uncertainty analysis for complex environmental models, PEST: Complete theory and what it means for modelling the real world. Watermark Numerical Computing, Brisbane, Australia

Enzenhoefer, R., T. Bunk, and W. Nowak. 2014. Nine steps to risk-informed wellhead protection and management: A case study. Groundwater, 52(S1), 161-174.

Ferré, T. P. 2017. Revisiting the relationship between data, models, and decision-making. Groundwater, 55(5), 604-614.

Fienen, M. N. 2013. We speak for the data. Groundwater, 51(2), 157.

Fiori, A., V. Cvetkovic, G. Dagan, S. Attinger, A. Bellin,.P. Dietrich, A. Zech., and G. Teutsch. 2016. Debates-Stochastic subsurface hydrology from theory to practice: The relevance of stochastic subsurface hydrology to practical problems of contaminant transport and remediation. What is characterization and stochastic theory good for?. Water Resources Research, 52(12), 9228-9234.

Freeze, R.A., J. Massmann, L. Smith, T. Sperling, and B. James. 1990. Hydrogeological decisionanalysis: 1. A framework. Groundwater 28 no. 5: 738-766.

Frind, E.O., and J.W. Molson. 2018. Issues and options in the delineation of well capture zones under uncertainty. Groundwater 56 no. 3: 366-376.

Frind, E.O., D.L. Muhammad, and J.W. Molson. 2002. Delineation of three-dimensional well capture zones for complex multi-aquifer systems. Groundwater 40, no. 6: 586-598.

Gallagher, M. R., and J. Doherty. 2007. Parameter interdependence and uncertainty induced by lumping in a hydrologic model. Water Resources Research, 43(5).

Gorelick, S.M., and C.M. Zheng. 2015. Global change and the groundwater management challenge. Water Resources Research 51 no. 5: 3031-3051.

Gürler, B., L. Hauber, and M. Schwander. 1987. Die Geologie der Umgebung von Basel mit Hinweisen über die Nutzungsmöglichkeiten der Erdwärme, Beiträge zur Geologischen Karte der Schweiz [Geology of Basel and surroundings, including remarks on the potential of geothermal energy use: contribution to the geological map of Switzerland]. National Hydrological and Geological Survey Geotechnical Committee, Bern, Switzerland.

Herckenrath, D., C.D. Langevin, and J. Doherty. 2011. Predictive uncertainty analysis of a saltwater intrusion model using null-space Monte Carlo. Water Resources Research 47.

Hunkeler, D., T. Laier, F. Breider, and O.S. Jacobsen. 2012. Demonstrating a natural origin of chloroform in groundwater using stable carbon isotopes. Environmental Science \& Technology 46 no. 11: 6096-6101.

Hunt, R.J., J.J. Steuer, M.T.C. Mansor, and T.D. Bullen. 2001. Delineating a recharge area for a spring using numerical modeling, Monte Carlo techniques, and geochemical investigation. Groundwater 39 no. 5: 702-712.

Illman, W.A. 2014. Hydraulic tomography offers improved imaging of heterogeneity in fractured rocks. Groundwater 52 no. 5: 659-684.

Illman, W.A., A.J. Craig, and X. Liu. 2008. Practical issues in imaging hydraulic conductivity through hydraulic tomography. Groundwater 46 no. 1: 120-132.

Izady, A., O. Abdalla, A. Joodavi, and M.J. Chen. 2017. Groundwater modeling and sustainability of a transboundary hardrock-alluvium aquifer in North Oman Mountains. Water 9 no. 3.

James, S.C., J.E. Doherty, and A.A. Eddebbarh. 2009. Practical postcalibration uncertainty analysis: Yucca Mountain, Nevada. Groundwater 47 no. 6: 851-869.

Keating, E.H., J. Doherty, J.A. Vrugt, and Q.J. Kang. 2010. Optimization and uncertainty assessment of strongly nonlinear groundwater models with high parameter dimensionality. Water Resources Research 46. 
Klaas, D.K.S.Y., and M.A. Imteaz. 2017. Investigating the impact of the properties of pilot points on calibration of groundwater models: case study of a karst catchment in Rote Island, Indonesia. Hydrogeology Journal 25 no. 6: 1703-1719.

Lavenue, M., and G. de Marsily. 2001. Three-dimensional interference test interpretation in a fractured aquifer using the pilot point inverse method. Water Resources Research 37 no. 11: 2659-2675.

Liu, G.S., J.J. Butler, E. Reboulet, and S. Knobbe. 2012. Hydraulic conductivity profiling with direct push methods. Grundwasser 17 no. 1: 19-29.

Llopis-Albert, C., D. Palacios-Marques, and J.M. Merigo. 2016. Decision making under uncertainty in environmental projects using mathematical simulation modeling. Environmental Earth Sciences 75 no. 19.

Majumder, P., and T. I. Eldho. 2017. Vectorized simulation of groundwater flow and contaminant transport using analytic element method and random walk particle tracking. Hydrological Processes, 31(5), 1144-1160.

McKenna, S.A., and A. Wahi. 2006. Local Hydraulic Gradient Estimator Analysis of Long-Term Monitoring Networks. Groundwater 44 no. 5: 723-731.

Meyer, P.A., M. Brouwers, and P.J. Martin. 2014. A three-dimensional groundwater flow model of the Waterloo Moraine for water resource management. Canadian Water Resources Journal 39 no. 2: $167-180$.

Meyer, R., P. Engesgaard, K. Hinsby, J.A. Piotrowski, and T.O. Sonnenborg. 2018. Estimation of effective porosity in large-scale groundwater models by combining particle tracking, autocalibration and $14 \mathrm{C}$ dating. Hydrology and Earth System Sciences, 22(9), 4843-4865.

Moeck, C., A. Affolter, D. Radny, H. Dressmann, A. Auckenthaler, P. Huggenberger, and M. Schirmer. 2017a. Improved water resource management for a highly complex environment using three-dimensional groundwater modelling. Hydrogeology Journal. 26: 133. https://doi.org/10.1007/s10040-017-1640-y

Moeck, C., D. Hunkeler, and P. Brunner. 2015. Tutorials as a flexible alternative to GUIs: An example for advanced model calibration using Pilot Points. Environmental Modelling \& Software 66: 78-86.

Moeck, C., D. Radny, A. Auckenthaler, M. Berg, J. Hollender, and M. Schirmer. 2017b. Estimating the spatial distribution of artificial groundwater recharge using multiple tracers. Isotopes in Environmental and Health Studies 53 no. 5: 484-499.

Moeck, C., D. Radny, P. Borer, J. Rothardt, A. Auckenthaler, M. Berg, and M. Schirmer. 2016. Multicomponent statistical analysis to identify flow and transport processes in a highlycomplex environment. Journal of Hydrology 542: 437-449.

Moeck, C., D. Radny, A. Popp, M. Brennwald, S. Stoll, A. Auckenthaler, M. Berg, and M. Schirmer. 2017c. Characterization of a managed aquifer recharge system using multiple tracers. Science of The Total Environment 609: 701-714.

Moeck, C., J. von Freyberg, and M. Schirmer. 2018. Groundwater recharge predictions in contrasted climate: The effect of model complexity and calibration period on recharge rates. Environmental Modelling \& Software, 103, 74-89.

Molson, J. W., and E. O. Frind. 2012. On the use of mean groundwater age, life expectancy and capture probability for defining aquifer vulnerability and time-of-travel zones for source water protection. Journal of Contaminant Hydrology, 127(1-4), 76-87.

Moore, C., and J. Doherty. 2005. Role of the calibration process in reducing model predictive error. Water Resources Research, 41(5).

National Groundwater Association (NGWA). 2017. Uncertainty in groundwater modeling, White Paper by the Groundwater Modeling Advisory Panel.

Neupauer, R. M., and J.L. Wilson. 2001. Adjoint-derived location and travel time probabilities for a multidimensional groundwater system. Water Resources Research, 37(6), 1657-1668.

Oliver, D.S., and Y. Chen. 2011. Recent progress on reservoir history matching: a review. Computational Geosciences 15 no. 1: 185-221.

Peeters, L. J. M., and C. Turnadge. 2019. When to account for boundary conditions in estimating hydraulic properties from head observations?. Groundwater.

Poeter, E.P., and M.C. Hill. 1997. Inverse models: A necessary next step in ground-water modeling. Groundwater 35 no. 2: 250-260. 
Rayne, T.W., K.R. Bradbury, and C.M. Zheng. 2014. Correct delineation of capture zones using particle tracking under transient conditions. Groundwater 52 no. 3: 332-334.

Renard, P. 2007. Stochastic hydrogeology: What professionals really need?. Groundwater, 45: 531541. doi:10.1111/j.1745-6584.2007.00340.x

Riva, M., L. Guadagnini, A. Guadagnini, T. Ptak, and E. Martac. 2006. Probabilistic study of well capture zones distribution at the Lauswiesen field site. Journal of Contaminant Hydrology 88 no. 1-2: 92-118.

Rojas, R., Feyen, L., and Dassargues, A. (2008). Conceptual model uncertainty in groundwater modeling: Combining generalized likelihood uncertainty estimation and Bayesian model averaging. Water Resources Research, 44(12).

Rosolem, R., H.V. Gupta, W.J. Shuttleworth, X.B. Zeng, and L.G.G. de Goncalves. 2012. A fully multiple-criteria implementation of the Sobol' method for parameter sensitivity analysis. Journal of Geophysical Research-Atmospheres 117.

Roubinet, D., H. H. Liu, and J.R. de Dreuzy. 2010. A new particle-tracking approach to simulating transport in heterogeneous fractured porous media. Water Resources Research, 46(11).

Sbai, M. A. 2018. A practical grid-based alternative method to advective particle tracking. Groundwater. 56: 881-892. doi:10.1111/gwat.12646

Schöniger, A., W.A. Illman, T. Wohling, and W. Nowak. 2015. Finding the right balance between groundwater model complexity and experimental effort via Bayesian model selection. Journal of Hydrology 531: 96-110.

Schwede, R.L., W. Li, C. Leven, and O.A. Cirpka. 2014. Three-dimensional geostatistical inversion of synthetic tomographic pumping and heat-tracer tests in a nested-cell setup. Advances in Water Resources 63: 77-90.

Sepulveda, N., and J. Doherty. 2015. Uncertainty analysis of a groundwater flow model in east-central Florida. Groundwater 53 no. 3: 464-474.

Sousa, M.R., E.O. Frind, and D.L. Rudolph. 2013. An integrated approach for addressing uncertainty in the delineation of groundwater management areas. Journal of Contaminant Hydrology 148: $12-24$.

Spottke, I., E. Zechner, and P. Huggenberger. 2005. The southeastern border of the Upper Rhine Graben: a 3D geological model and its importance for tectonics and groundwater flow. International Journal of Earth Sciences 94 no. 4: 580-593.

Strasser, D., H.J. Lensing, T. Nuber, D. Richter, S. Frank, N. Goeppert, and N. Goldscheider. 2015. Improved geohydraulic characterization of river bed sediments based on freeze-core sampling - Development and evaluation of a new measurement approach. Journal of Hydrology 527: 133-141.

Srivastava, D., and R.M. Singh. 2015. Groundwater System Modeling for Simultaneous Identification of Pollution Sources and Parameters with Uncertainty Characterization. Water Resources Management 29 no. 13: 4607-4627.

Sudicky, E.A., and P.S. Huyakorn. 1991. Contaminant Migration in Imperfectly Known Heterogeneous Groundwater Systems. Reviews of Geophysics 29: 240-253.

Tonkin, M., and J. Doherty. 2009. Calibration-constrained Monte Carlo analysis of highly parameterized models using subspace techniques. Water Resources Research 45.

Vesselinov, V.V., S.P. Neuman, and W.A. Illman. 2001. Three-dimensional numerical inversion of pneumatic cross-hole tests in unsaturated fractured tuff 2. Equivalent parameters, highresolution stochastic imaging and scale effects. Water Resources Research 37 no. 12: 30193041.

Visser, A., R. Heerdink, H.P. Broers, and M.F.P. Bierkens. 2009. Travel time distributions derived from particle tracking in models containing weak sinks. Groundwater, 47(2), 237-245.

Wang, Y., and K. Brubaker. 2015. Multi-objective model auto-calibration and reduced parameterization: exploiting gradient-based optimization tool for a hydrologic model. Environmental Modelling \& Software, 70, 1-15.

White, J. T., M. N. Fienen, and J.E. Doherty. 2016. A python framework for environmental model uncertainty analysis. Environmental Modelling \& Software, 85, 217-228. 
Willmann, M., G. W. Lanyon, P. Marschall, and W. Kinzelbach. 2013. A new stochastic particletracking approach for fractured sedimentary formations. Water Resources Research, 49(1), 352-359.

Zheng, C. 1994. Analysis of particle tracking errors associated with spatial discretization. Groundwater, 32(5), 821-828.

Zheng, C.M., and S.M. Gorelick. 2003. Analysis of solute transport in flow fields influenced by preferential flowpaths at the decimeter scale. Groundwater 41 no. 2: 142-155.

Zschornack, L., G.C. Bohling, J.J. Butler, and P. Dietrich. 2013. Hydraulic profiling with the directpush permeameter: Assessment of probe configuration and analysis methodology. Journal of Hydrology 496: 195-204. 


\section{List of figures}

Figure 1: Study area showing a) location in northwest Switzerland with b) urban and industrial zones. c) Simplified geology map with the bedrock geological units. The flexure zone consists of Tertiary, Jura, Keuper and Muschelkalk sediments. The overlying Quaternary deposits are not shown. d) Schematic cross-section ( $\left.A^{\prime}-A\right)$ with geological units, watertable elevations and groundwater flow directions.

Figure 2: Model discretization, boundary conditions and geological units.

Figure 3: Model domain with pilot point locations (green circles with black dots). Monitoring wells are shown for the Quaternary and Bedrock aquifer. The three predictions $(P)$ for the linear uncertainty analysis are shown in orange.

Figure 4: Scatter plot between observed (x-axis) and simulated (y-axis) hydraulic heads for the 116 monitoring wells. The ensemble range (880 parameter sets) is displayed as vertical bars while the ensemble mean values are shown with black symbols.

Figure 5: $K$ distribution for the bedrock for four randomly selected parameter realizations ( $a$ d). The $K$ values are shown as $\log _{10}$ values, where red and blue areas show higher and lower $K$, respectively.

Figure 6: Interpolated standard deviation map of $\log _{10} \mathrm{~K}$ values from 880 model parameter sets. Note a value of 1 represents a variation of one order of magnitude in K values

Figure 7: Spatial pathline density distributions of the ensemble backward tracked pathlines for a) the pumping wells, b) the sand-gravel aquifer and c) the bedrock aquifer. Particle tracking was carried out for 880 calibrated model realizations. 
Figure 8: Uncertainty reduction estimates of three different predictions at the pumping wells (see also Fig. 3). The larger the bar, the greater the reduction in uncertainty as a result of the inverse calibration process.

Figure 9: Reduction in prediction variance (uncertainty) by parameters (hydraulic conductivity $\left(K_{-}^{*}\right)$, river transfer rates $\left(R_{-}^{*}\right)$ and boundary conditions $\left(M_{-}^{*}\right)$. The larger the bar, the greater the reduction in uncertainty as a result of the inverse calibration process. 

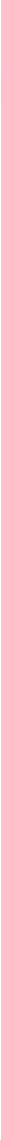


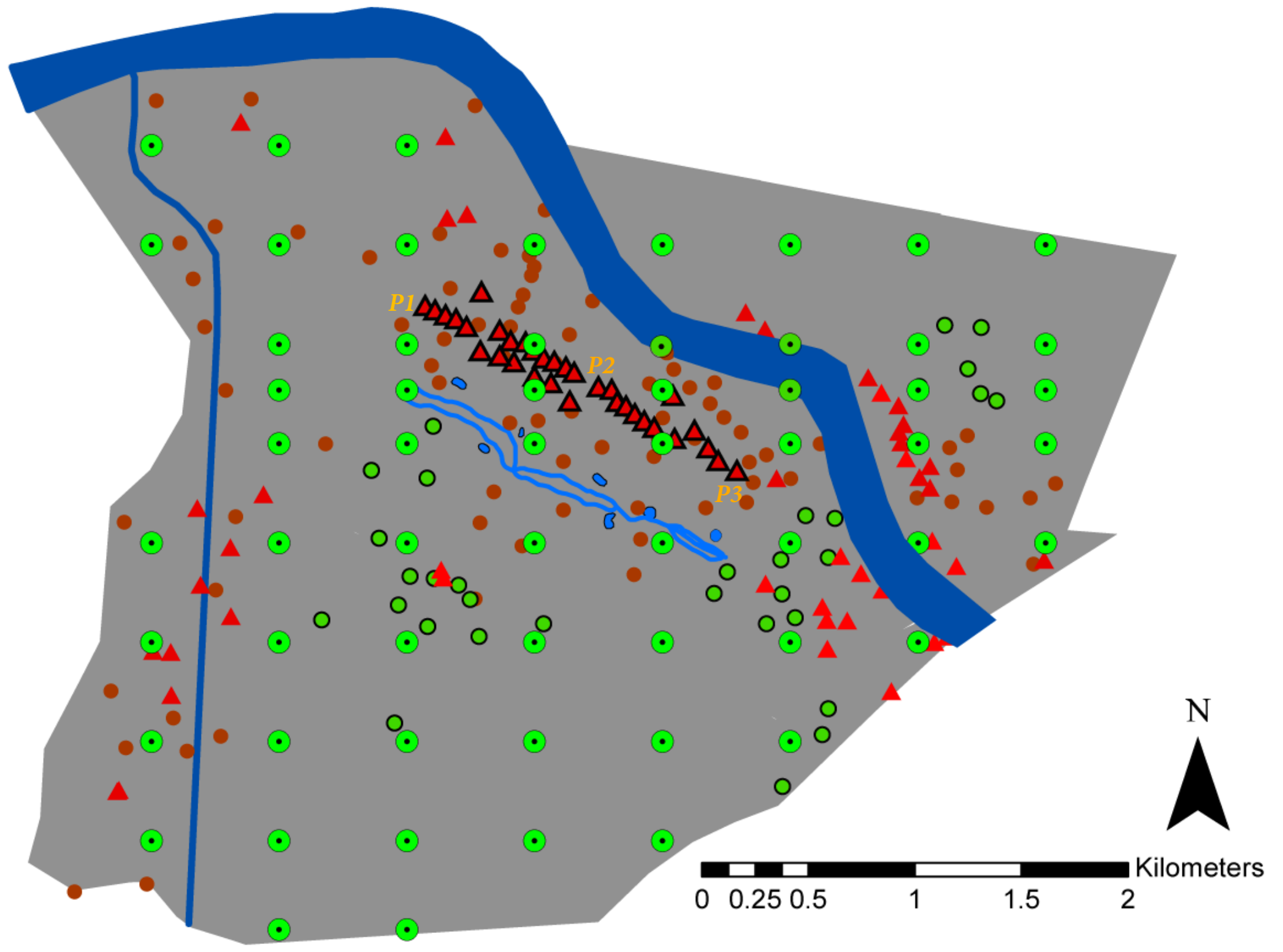

\section{Legend}
A Industrial well
(3) Infiltration Pond
- Pilot Point
Monitoring well $\triangle$ Drinking water well
- Quaternary aquifer $\longrightarrow$ River
O Bedrock aquifer _ Infiltration channel 
a) Sand-gravel aquifer

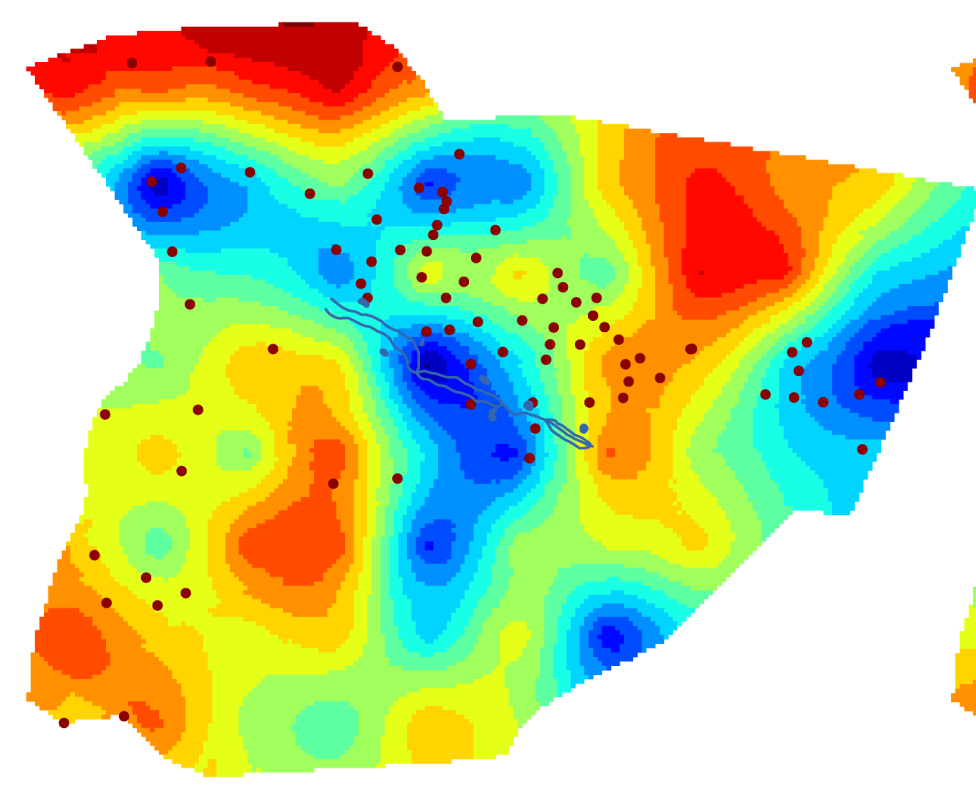

b) Bedrock aquifer

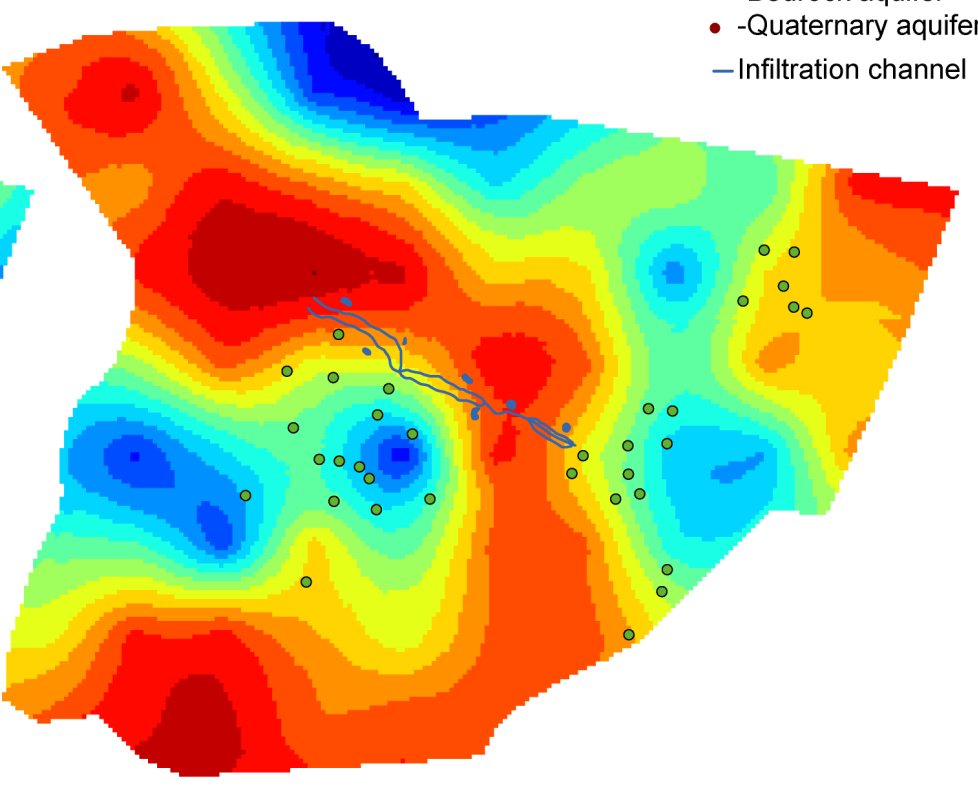

0.9

0.8

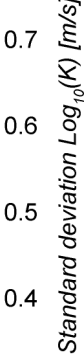

0.3

0.2 

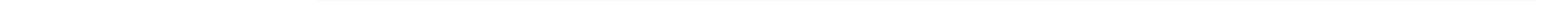


\section{Prediction (P)}

particle tracking path length

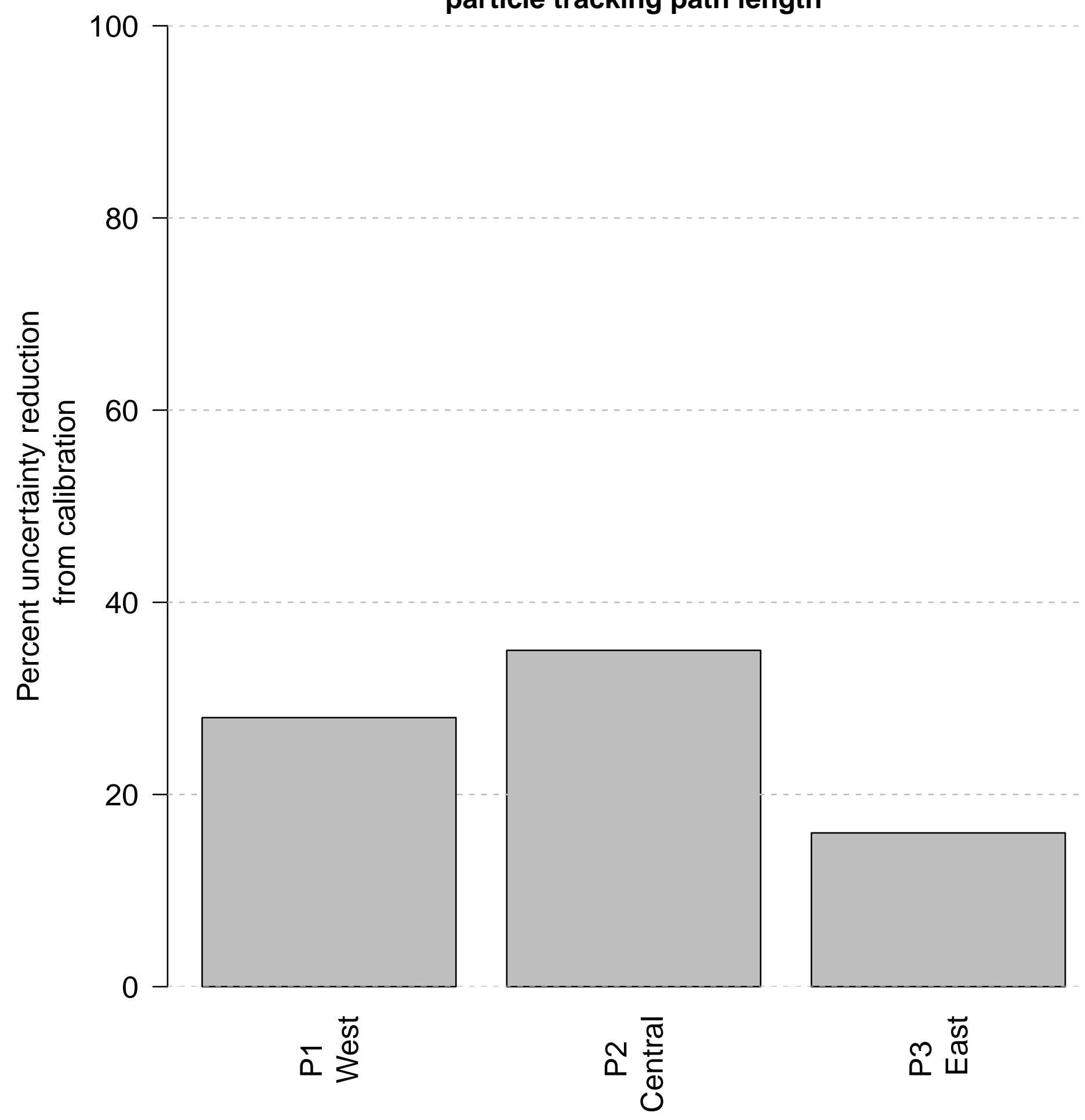


